\title{
A Case Study of the Development of In-service Teachers' Concept Images of the Derivative
}

\author{
Botshiwe Likwambe and Iben Maj Christiansen \\ Faculty of Education, University of KwaZulu-Natal, South Africa \\ likwamsh@dynalogic.co.za and christianseni@ukzn.ac.za
}

\begin{abstract}
This research focuses on the development of the concept images of the derivative concept of five students enrolled in the in-service programme Advanced Certificate in Education (ACE) at the University of KwaZulu-Natal, Pietermaritzburg campus. For comparison, the concept images of two qualified teachers not enrolled in the programme were included. The findings show that of the five ACE students who were interviewed, only one had a profound concept image in all the three layers of the derivative, with multiple representations as well as connections among representations within the layers. This one student also passed the calculus module with a distinction. The other four students had the ratio layer and graphical representation in their concept images, while the other layers and representations were pseudo-structural with very few connections. Two of these students passed the calculus module, while the other two failed. All the students showed progression in their concept images, which can probably be credited to the ACE calculus module. However, it is clear that even upon completion of this module, many practicing teachers have concept images of the derivative which are not encompassing all the layers and more than one or two representations. The research suggested that historically disadvantaged students experience continued inequalities in learning. The research also showed the need to expand the framework of Zandieh (2000), developed to describe concept images of derivative.
\end{abstract}

\section{According to Tall (1993):}

calculus represent the first time in which the student is faced with the limit concept, involving calculations that are no longer performed by simple arithmetic and algebra, and infinite processes that can only be carried out by indirect arguments. (p. 23)

Research from several countries indicate that many students rely on memorisation, struggle to translate realistic problems into calculus, and appear to prefer procedural methods rather than pursuing conceptual understanding (Aspinwall, Shaw, \& Presmeg, 1997; Selden, Selden, Hauk, \& Mason, 1999; Tall, 1993; White \& Mitchelmore, 1996). Their concept images are often limited, including only some aspects of the notion of derivative (Amit \& Vinner, 1990; Bezuidenhout, 1998; Orton, 1983; Thompson, 1994; Ubuz, 2001; Zandieh, 2000).
In South Africa, Bezuidenhout (2001) found that many mathematics lecturers have acknowledged that, while the first year students can find limits, derivatives and integrals, they lack conceptual understanding of basic calculus. His study on students from three different South African Universities show that a large number of first year students have a weak understanding of basic calculus concepts and that their understanding is mainly procedural rather than conceptual.

Zandieh's results (2000) show that the nine students in her study had a wide variety of representational preferences. These students had different concept images of the derivative concept and these included the basic representations that focuses on rate and slope as a way of describing the derivative. The results also show that there is no hierarchy in the layers of the concept (see 
theoretical framework); this means that the students may learn the layers in any order.

A calculus reform movement evolved in the USA during the late 1980s because of the high number of dropouts from the calculus course and poor performances by those who continued with the course (Bowie, 1998). Though this reform did affect South Africa as well, we believe the South African situation is still very problematic given the number of unqualified teachers (cf. Parker, 2004). The ACE course was developed to upgrade the competencies of un- or under-qualified educators, but it was our impression that the courses were not sufficiently effective on a conceptual level. It was on this basis we chose to investigate the progression of the ACE students' concept images of the derivative.

Studies which have been conducted in South Africa on the derivative concept were mainly on one aspect of the derivative using one representation. This study involves all three layers and various representations of the derivative concept, which we will now expand on in the discussion of our theoretical framework.

\section{Theoretical Framework}

In the research, we drew on Zandieh's theoretical framework for the derivative (1997; 2000), which draws on the notion of concept images (Tall \& Vinner, 1981; Thompson, 1994), Sfard's (1991) work on the process-object duality of mathematical concepts and work on concept representations (Goldin \& Shteingold, 2001; Gravemeijer, Lehrer, van Oers, \& Verschaffel, 2003; Vinner \& Dreyfus, 1989). Zandieh's framework was also informed by the whole community of mathematics, including researchers, teachers, students and textbooks.

According to Sfard (1991), a concept can be seen as a process and as an object. Generally, the process aspect precedes the object aspect. In describing the process-object framework, Zandieh (2000) points out that:

The underlying structure of any representation of the concept of the derivative can be seen as a function whose value at any point $[x]$ is the limit of the ratio of differences

$$
f^{\prime}(x)=\lim _{h \rightarrow 0} \frac{f(x+h)-f(x)}{h}
$$

(p.106, author's notation)
Zandieh (1997, 2000) claims that the derivative has three layers: ratio, limit and function. Each of these three layers can be viewed as a process and as an object. Also, each of these layers can be represented graphically, verbally, paradigmatically (physically) and symbolically.

\section{The ratio layer}

The ratio layer is the part of the derivative that deals with the average gradient, represented in Leibniz notation as $\frac{\Delta y}{\Delta x}$. The ratio as a process is seen as a process of division of the numerator by the denominator, and as an object a ratio is seen as a pair of integers or as the outcome of the division process.

In symbolic representation the ratio as the average gradient between two points $\left(x_{0}, f\left(x_{0}\right)\right)$ and $\left(x_{0}+h, f\left(x_{0}+h\right)\right)$ can be represented as $\frac{f\left(x_{0}+h\right)-f\left(x_{0}\right)}{h}$. The ratio layer can also be represented graphically as a slope of a secant which is calculated as $\frac{\text { difference in } y}{\text { difference in } x}$, and in terms of situational representation, average velocity can be represented as a ratio when one is calculating $\frac{\text { change in displacement }}{\text { change in time }}$. All of the representations have both process and object aspects.

\section{The limit layer}

The limit as a process is seen as taking the limit and as an object it is seen as the limit value. The limit layer can be represented in several different ways. The limiting process of the gradient can be represented in Leibniz notation as $\lim \frac{\Delta y}{\Delta x}$ and in symbolic representation as $f^{\prime}\left(x_{0}\right)=\lim _{h \rightarrow 0} \frac{f\left(x_{0}+h\right)-f\left(x_{0}\right)}{h}$. Note the use of $x_{0}$ here, to indicate that at the limit layer, the derivative is found at a point.

The limit layer can also be represented graphically. For the limiting process, one focuses at a point on a curve and keeps it fixed while choosing other points on the curve increasingly closer to the fixed point. Connecting the fixed point to each of the other points in turn, a number of secants are drawn, 
which will approach the tangent of the curve, referred to by Thompson (1994) as the sliding secant. So the limiting process will be to approach the tangent to the curve at a given point. When someone understands that the gradient of the tangent is also the gradient of the curve at that point (a matter of existence and uniqueness which we will not touch upon here, but to note that it is an aspect about which Zandieh's framework remains silent), they will have grasped the fundamental assumption of the limit layer in the derivative concept.

\section{The function layer}

As a process, a function is described by Vinner and Dreyfus (1989) as a correspondence between two non-empty sets, and as an object they describe it as a set of ordered pairs. In the derivative's function layer, the order pairs are $\left(x, f^{\prime}(x)\right)$. The function layer can be represented in many different ways. The derivative can be represented in Leibniz notation as $\frac{d y}{d x}$. In symbolic representation, the derivative function, that is the gradient of the curve at every point $(x, f(x))$, is represented as $f^{\prime}(x)=\lim _{h \rightarrow 0} \frac{f(x+h)-f(x)}{h}$. In situational representation, one looks at the instantaneous velocity at any point in time.

\section{Pseudo-structural objects}

If the student does not have the internal structure as part of her/his concept image, then a pseudostructural conception occurs. According to Sfard (1991), a pseudo-structural object is an intuitive understanding which does not involve an understanding of the process underlying the object. Zandieh (2000) points out that the use of pseudostructural objects allows the student to formulate basic understandings of the derivative concept which differ from each other, and as a result, the students' understanding develops from partial to a more complete understanding with only a few aspects of the concept missing

\section{Expanding Zandieh's framework}

While Zandieh acknowledges that it is in the perceived connection between the various components of the concept image that the concept exists for the individual, her framework does not allow her to identify the extent to which the students make such connections. We want to emphasise what becomes hidden in Zandieh's framework, namely that strong concept images exist in connections across layers and representations. For instance, it is desirable that learners and teachers alike will look at a graphical illustration of a derivative and interpret it symbolically or vice versa. It therefore becomes necessary to enhance the framework's ability to capture such connections.

Zandieh's framework focuses on the conceptual layers of the derivative. However, many learners and educators have procedural (distinct from process aspects of concepts) knowledge of the derivative. For instance, our data showed that some of the interviewees could find the derivative of a given function without necessarily showing concept images falling within Zandieh's framework. To capture this aspect, we found it necessary to expand the theoretical framework, so we had to include 'instrumental understanding' in order to include the only learning exhibited by most of the interviewees. Lithner (2003) describes instrumental understanding as mastering of a rule or procedure. A student can master a rule or a procedure without any insight into the reasons that make it work, but some students can master a rule or procedure and at the same time have insight into the reasons that make it work. Here, we use 'instrumental understanding' simply to refer to the ability to use a rule. If a student also understands the background to the rule, we will indicate this in our coding of the data.

\section{Methodology}

We used a case study approach with the unit of analysis being the ACE students at the University of KwaZulu-Natal, Pietermaritzburg campus. This was a convenience sample.

However, the students attending the ACE in Pietermaritzburg come from a wide range of backgrounds, though mostly historically disadvantaged. In that sense, there is no reason to believe that this group of students was markedly different in their concept knowledge from students at other higher education institutions across South Africa.

From the students attending the calculus module, we randomly selected students with the only criteria that there would be at least one high performing, one medium performing, and one low performing student. More than five students agreed to participate, but failed to make themselves 
available for interviewing, despite repeated prompting, and we ended with a sample of two high performing, one medium performing, and two low performing students.

While some high school classes in South Africa are being taught by 'teachers' who have not completed Grade 12 themselves, the ACE students in this research had all obtained their school leaving certificates. Two of them had been taught introductory calculus at high school and the other three had not. All five students completed a three year Teaching Diploma at different colleges of education, specialising in the teaching of mathematics. As part hereof, they were taught differential calculus. Two of the students have never taught calculus since they completed their diploma. During the ACE programme, they were all reintroduced to differential calculus, especially the derivative concept.

The two teachers outside of the ACE programme who took part in this research both have a BSc in Mathematics and a Higher Diploma in Education from the historically white University of Natal. They are teaching at a historically advantaged school. Megan has been teaching for more than ten years, while Deanne has been teaching for two years.

Table 1 gives an overview of the interviewees' background and current situation. ${ }^{1}$ Here, as in the analysis, pseudonyms have been used.

The first author conducted three open ended interviews with each student. Matthew's first interview was done one week before his examinations, the second interview was done just after the examinations and the last interview was done four months after the second interview. For the other four students, the first interview was done halfway into the course and the second interview at the end of the course just before the examinations.
The third interview was done four months after the second interview. The two non-ACE teachers were interviewed once, each, as there was no reason to assume that their concept images would change drastically over time. The interviews were recorded and transcribed.

During the interviews, the students and educators were asked open-ended questions. Choosing suitable questions to ask the students was a big challenge. The question, "What is a derivative?" seemed to be threatening to the students because it may be perceived as an assessment question. Thus, it could have limited the possible explanations the students could have given, which is why it was only asked at the end of the interview. Hence the question "What comes to your mind when I say derivative?" was used, as it also directly searches for concept images rather than concept definitions. After their answer, where necessary, the researcher followed up with deliberately vague prompts such as "What else comes to your mind?", "Tell me more about that", "How are all the parts of the formula connected?”. Examples were asked for, where she deemed it necessary or useful in obtaining more insight into their concept images.

The interviewees have concept images that they have constructed, experienced and shared and which will be elicited as they interact with the researcher (cf. Guba \& Lincoln, 1989). Through interacting with their lecturer and classmates, the students have created meaning and made sense of the derivative concept. Therefore, we worked from the assumption that the interviewees had concept images which did not change substantially because they were asked about them - though we recognise that some alterations of concept images are likely to occur as students are prompted to summarise or reflect on their knowledge and learning. Another assumption was that what the students say during the interviews will reasonably reflect their concept

Table 1: The background and current situation of interviewees

\begin{tabular}{|c|c|c|c|c|c|c|}
\hline $\begin{array}{c}\text { Pseudonym of } \\
\text { Interviewee }\end{array}$ & $\begin{array}{c}\text { Did Calculus } \\
\text { in Matric? }\end{array}$ & $\begin{array}{c}\text { Type of school } \\
\text { where matriculated }\end{array}$ & $\begin{array}{c}\text { Did Calculus } \\
\text { at college? }\end{array}$ & $\begin{array}{c}\text { Number of } \\
\text { years teaching }\end{array}$ & $\begin{array}{c}\text { Teach matric } \\
\text { (grade 12)? }\end{array}$ & $\begin{array}{c}\text { Number of years } \\
\text { teaching } \\
\text { Calculus }\end{array}$ \\
\hline Matthew & Yes & Ex Model C & Yes & 5 & Yes & 3 \\
\hline Themba & No & Village School & Yes & 10 & Yes & 10 \\
\hline Nompilo & Yes & Township School & Yes & 5 & No & 0 \\
\hline Ayanda & No & Mission School & Yes & 6 & No & 0 \\
\hline Mandisa & No & Township School & Yes & 10 & Yes & 0 \\
\hline Megan & Yes & Ex Model C & Yes & $>10$ & Yes & $>10$ \\
\hline Deanne & Yes & Ex Model C & Yes & 2 & Yes & 1 \\
\hline
\end{tabular}


images - though we do acknowledge that it is possible that only parts of their concept images were elicited during the interviews.

\section{Analysis instrument}

Our instrument used Zandieh's instrument developed from her theoretical framework as a starting point. We added three aspects to it, reflecting the discussion in the previous section:

- instrumental understanding was added as a separate category

- arrows were added to reflect connections among the representations revealed in the interviews

- a non-layer was added to reflect situations where interviewees' responses could not be classified in any of the three layers.

The result was the 'matrix' in Figure 1.

Following Zandieh, we used shaded circles to denote a complete understanding of the representation and the process involved, and unshaded circles to denote pseudo-structural understanding. Instrumental understanding characterised by the interviewee not showing an understanding of reasons behind a rule is always illustrated by an un-shaded circle. The arrows from one representation to the other show any connections.

Next, we illustrate the use of the instrument on a number of the interviews.

\section{Analysis}

\section{Nompilo's case}

\section{Interview two}

Botshiwe: When I say derivative what comes to your mind?

Nompilo: Slope comes to my mind.

Bosthiwe: Is there a situation where we can use this?

Nompilo: We use the derivative to find the slope of a graph.

Botshiwe: What else comes to your mind?

Nompilo: The formula of the derivative comes to my mind.

Botshiwe: Tell me more about the formula

Nompilo: It is (she writes $\frac{d y}{d x}$ ), we use it to find the derivative.

Botshiwe: What else comes to your mind when I say derivative?

Nompilo: The chain rule and implicit differentiation.

Botshiwe: Anything else?

Nompilo: Nothing.

Placing an un-shaded circle in the slope column

\begin{tabular}{|c|c|c|c|c|c|c|}
\hline & \multicolumn{5}{|c|}{ REPRESENTATION } \\
\hline $\begin{array}{c}\text { Process-Object } \\
\text { Layer }\end{array}$ & Graphical & Verbal & $\begin{array}{c}\text { Paradigmatic/ } \\
\text { Physical }\end{array}$ & Symbolic & Other & Instrumental understanding \\
\hline Ratio & Slope & Rate & Velocity & & & \\
Limit & & & & & & \\
Function \\
Non-layer
\end{tabular}

Figure 1: Theoretical framework (Source: Adapted from Zandieh, 2000)

\begin{tabular}{|l|c|c|c|c|c|}
\hline & \multicolumn{3}{|c|}{ REPRESENTATION } \\
\cline { 1 - 4 } $\begin{array}{c}\text { Process-Object } \\
\text { Layer }\end{array}$ & Graphical & Verbal & $\begin{array}{c}\text { Paradigmatic/ } \\
\text { Physical }\end{array}$ & Symbolic & \multirow{2}{*}{ Instrumental understanding } \\
\hline Ratio & Slope & Rate & Velocity & Difference Quotient & \multirow{2}{*}{$?$} \\
\hline Limit & & & & & \\
\cline { 1 - 2 } Function & & & & & \\
\hline Non-layer & & & & & \\
\hline
\end{tabular}

Figure 2: Nompilo's description of the derivative 
and the non-layer row, the diagram (Figure 2) reflects that Nompilo describes the derivative as slope. If she had described the slope as a ratio, the circle would have been in the ratio row. A circle with a question mark is in the instrumental understanding column because Nompilo mentions that the formula comes to her mind, but it is not clear if she is able to use the formula.

\section{Interview Three}

Botshiwe: What comes to your mind when I say derivative?

Nompilo: Slope or steepness of a graph.

Botshiwe: Tell me more about the slope.

Nompilo: The slope is $\frac{y_{2}-y_{1}}{x_{2}-x_{1}}$ and this is the gradient. But the gradient at a point is

$$
f^{\prime}(x)=\lim _{h \rightarrow 0} \frac{f(x+h)-f(x)}{h} .
$$

Botshiwe: In the formula for gradient at a point, how are the different parts connected to each other?

Nompilo: $\quad f(x+h)-f(x)$ is change in $y$ and $h$ is change in $x$. The limit helps us to find the gradient at a point.

Botshiwe: Is there any situation where we can use the slope in real life?

Nompilo: There is but I don't remember.

Botshiwe: Is there anything else that comes to your mind about the derivative?

Nompilo: I know we find the derivatives in Trigonometry.

Botshiwe: How do you do that?

Nompilo: I don't remember.

Botshiwe: Sum up and tell me, what is a derivative?

Nompilo: A derivative tells us about the slope of a function.

The shaded circle in the ratio row and slope column in Figure 3 reflects that Nompilo describes the derivative as a slope which is change in $y$ divided by change in $x$, which means that she has the ratio layer represented graphically in her concept image. The un-shaded circle in the slope column and limit row indicates that this layer of her concept image is pseudo-structural; she knows it involves the limit but does not explain how. The un-shaded circle in the limit row and the difference quotient column indicates that Nompilo has symbolic representation of slope in her concept image but this is again pseudo-structural. Nompilo explains the calculations involved in the symbolic expression of the derivative at the ratio layer, which is why the circle in the ratio row and difference quotient is shaded.

The arrows indicate that she makes connections between the graphical representation and the symbolic representation, because she describes the derivative as a slope and then gives the symbolic representation of the slope at the ratio layer. The arrows at the limit layer show that there is a connection between graphical representation and the symbolic representation, because she describes the derivative as the gradient at a point and then gives the symbolic representation of the gradient at a point.

\section{Development in Nompilo's concept image}

While looking at the results of Nompilo's three interviews, we notice that generally the slope is the main representation in her concept image, and the ratio layer the dominant layer. While it is possible that she could have the function layer and other representations of the derivative as part of her concept image and not exhibited them during the interview, we find this unlikely given Nompilo's stated difficulties with recalling anything else of relevance. Nompilo's concept image did not seem to change during the module (from interview 1 not shown here - to interview 3 ) but seems to have been strengthened after the module.

\begin{tabular}{|c|c|c|c|c|c|}
\hline & \multicolumn{5}{|c|}{ REPRESENTATION } \\
\hline $\begin{array}{c}\text { Process-Object } \\
\text { Layer }\end{array}$ & Graphical & Verbal & $\begin{array}{c}\text { Paradigmatic/ } \\
\text { Physical }\end{array}$ & Symbolic & \multirow{2}{*}{ Instrumental understanding } \\
\hline & Slope & Rate & Velocity & Difference Quotient & \\
\hline \multicolumn{5}{|l|}{ Ratio } & \\
\hline \multicolumn{5}{|l|}{ Limit } & \\
\hline \multicolumn{5}{|l|}{ Function } & \\
\hline Non-layer & & & & & \\
\hline
\end{tabular}

Figure 3: Further analysis of Nompilo's view 


\section{Deanne's Concept Image}

Deanne is a qualified educator who has been teaching for two years.

Botshiwe: When I say derivative what comes to your mind?

Deanne: Slope and rate of change.

Botshiwe: Tell me more about the slope.

Deanne: We use the derivative to find more about the slope. If you know the formula for the slope then you can find out the rate of change whether it's time, it depends on what you are looking at.

Botshiwe: Tell me more about the formula for the slope.

Deanne: The formula I was talking about is something like $f(x)=3 x^{3}-2 x^{2}+x-5$ which is the formula of a graph. Do you want to know the

Botshiwe: Yes. formula of finding the slope of this graph?

Deanne: To find the derivative of

$f(x)=3 x^{3}-2 x^{2}+x-5$, initially one would do it from first principles which would be finding the average gradient between two points on the graph.

$f(x)=3 x^{3}-2 x^{2}+x-5$ would be at $x$ on the graph, then you would find another point on the graph say $\mathrm{f}(x+h)$. To do that you

would substitute $x+h$ into $3 x^{3}-2 x^{2}+x-5$ which means

$f(x+h)$

$=3(x+h)^{3}-2(x+h)^{2}+(x+h)-5$

To find the derivative you would then find the difference between these two and divide by h. And then we take the limit of that as $h$ tends to zero. This is written as

$$
f^{\prime}(x)=\lim _{h \rightarrow 0} \frac{f(x+h)-f(x)}{h} .
$$

Botshiwe: How are the different parts of the formula connected?

Deanne: $\quad f(x+h)-f(x)$ is the difference in $y$ and $h$ is the difference in $x$.

Botshiwe: How does the limit fit in?

Deanne: The limit fits in because we are looking at average slope between two points and we want to find the slope at a specific point.

Botshiwe: How would one use the slope in real life?

Deanne: If you were trying to model population growth you might have a formula for that population growth and you might want to find what the rate of change of population is over time. So then you would find the derivative of that formula and that would let you see at various points in time what the rate of change is when the population was increasing at that stage or decreasing.

Botshiwe: You mentioned rate of change. Tell me more about it.

Deanne: OK the rate of change. What we are looking at, is the rate of change between two points and the derivative is the instantaneous rate of change. Which means we are looking at how the function is changing at a specific point.

Botshiwe: Is there anything else that comes to your mind about the derivative?

Deanne: Looking at maximum and minimum values in a graph is one of the things that one would use the derivative for. And one does that by looking at local maxima and local minima. When the derivative is zero you will find the local maximum or local minimum in a graph because your instantaneous rate of change becomes zero as the graph reaches a maximum or minimum.

Botshiwe: What is a derivative?

Deanne: It is the instantaneous rate of change.

Deanne describes the derivative as slope and gives the formula of finding the slope. That is why there is a shaded circle in the ratio row and slope column in Figure 4. She is able to explain the underlying idea behind the common rule of finding the derivative of a function. This shows that she has a strong ratio layer which is represented graphically in her concept image. She also describes the derivative as rate of change and explains that "it is a formula that would let you see at various points in time what the rate of change is", so she has the function layer in her concept image. Deanne gives the definition of the derivative function and

\begin{tabular}{|c|c|c|c|c|c|}
\hline & \multicolumn{5}{|c|}{ REPRESENTATION } \\
\hline $\begin{array}{c}\text { Process-Object } \\
\text { Layer }\end{array}$ & Graphical & Verbal & $\begin{array}{c}\text { Paradigmatic/ } \\
\text { Physical }\end{array}$ & Symbolic & \multirow[t]{2}{*}{ Instrumental understanding } \\
\hline & Slope & Rate & Velocity & Difference Quotient & \\
\hline \multicolumn{5}{|l|}{ Ratio } & \\
\hline \multicolumn{5}{|l|}{ Limit } & \\
\hline \multicolumn{5}{|l|}{ Function } & \\
\hline Non-layer & & & & & \\
\hline
\end{tabular}

Figure 4: Deanne's interpretation of the derivative 
explains the calculations that are involved. This is shown by the shaded circle in the ratio row and the difference quotient column and also the limit row and difference quotient column which shows that she has a strong symbolic representation of the ratio layer in her concept image. The shaded circle in the limit row and slope column illustrates that Deanne explains how the limit is involved in finding the derivative. She also explains instantaneous rate of change, which is why there is a shaded circle in the limit row and rate of change column.

Her concept image of the derivative is spread across all but one representation. Deanne describes the derivative as slope and gives the formula of the slope which shows that she has connections between graphical and symbolic representations at the ratio layer. She also describes the derivative as the slope at a point and explains the process using the formula. This indicates that she has connections between the graphical and symbolic representations at the limit layer. Deanne has connections between the graphical and verbal representations because she mentions that if one knows the formula of the slope they can find rate of change.

From these results, one can conclude that Deanne has a strong concept image of the derivative which is spread across all representations except velocity which does not occur. She might have had velocity in her concept image but chosen not to mention it during the interview. The function layer is least strong in her concept image because it has one representation. These results also show that she has several connections among representations in her concept image.

\section{Findings: developments in concept images of all interviewees}

Table 2 shows the layers and representations of the derivative concept, preferred by the interviewees when they were asked, "What comes to your mind when I say derivative?" This offers an overview of the first level of analysis.

All five students at some stage showed that they had instrumental understanding of the derivative concept. It is also evident from the interviews that all five students have the slope as (one of) their main representation(s) of the derivative, while the limit layer is pseudo-structural for most of the interviewees and the function layer rarely exhibited. The analysis of Matthew, Deanne and Megan's results show that they display all three layers. Unlike Zandieh's students, it appears that these students are more likely to develop the ratio layer before the limit layer, with the function layer as the last aspect to be developed.

The results of Mandisa, Nompilo, Ayanda and Themba show consistencies across representations within the layers. This means that in the ratio layer for example, if their understanding is pseudostructural in one representation, then it will be pseudo-structural in the other representations of the same layer. These four students have one or two representations of a layer. Their representations do not exceed two, while Matthew's interviews show that he has more than two representations of a layer.

In all the three interviews, Ayanda and Themba do not exhibit symbolic representations in their concept images, although Ayanda is repeating the module and Themba is a medium performing

Table 2: Interviews summary

\begin{tabular}{|l|c|c|c|}
\hline Interviewee & $\begin{array}{c}\text { Interview } \\
\text { One }\end{array}$ & $\begin{array}{c}\text { Interview } \\
\text { Two }\end{array}$ & $\begin{array}{c}\text { Interview } \\
\text { Three }\end{array}$ \\
\hline Matthew & R+S & R+S+V & R+V+S \\
\hline Representation & Ratio & ratio/limit & ratio/limit \\
\hline Dominant Layer & & & \\
\hline Themba & $\mathrm{S}$ & $\mathrm{R}+\mathrm{S}$ & $\mathrm{R}+\mathrm{S}$ \\
\hline Representation & Limit & Ratio & limit \\
\hline Dominant Layer & & & \\
\hline Mandisa & None & $\mathrm{S}$ & $\mathrm{S}$ \\
\hline Representation & & & \\
\hline Dominant Layer & & & \\
\hline Ayanda & $\mathrm{I}$ & $\mathrm{I}$ & $\mathrm{S}$ \\
\hline Representation & None & non-layer & ratio \\
\hline Dominant Layer & & & \\
\hline Nompilo & $\mathrm{I}$ & $\mathrm{S}$ & $\mathrm{S}$ \\
\hline Representation & $\mathrm{S}$ & & \\
\hline Dominant Layer & None & non-layer & ratio \\
\hline Megan & & & \\
\hline Representation & $\mathrm{S}+\mathrm{R}$ & & \\
\hline Dominant Layer & ratio/limit & & \\
\hline Deanne & & & \\
\hline Representation & ratio/limit & & \\
\hline Dominant Layer & & & \\
\hline
\end{tabular}

$\mathrm{R}=$ Rate of change $\mathrm{S}=$ Slope $\mathrm{V}=$ Velocity

$\mathrm{I}=$ Instrumental understanding 
student. Mandisa, Ayanda and Nompilo do not have verbal representation in their concept images while Themba and Matthew mainly have pseudostructural verbal representation.

Matthew shows a steady development of the velocity representation which starts as pseudostructural in the ratio layer by the first interview. By the second interview, velocity has become more profound in the ratio layer and pseudostructural in the limit layer. The third interview shows a strong understanding of the derivative in the ratio and limit layers with velocity as a representation. Themba and Ayanda have a pseudo-structural understanding of the velocity representation in the non-layer during their second interviews, while Mandisa and Nompilo do not have velocity as their representation. These students have been through the same course and the slope has been a strong part of their concept image which has been evoked by the course. Even though this is the case, the students display obvious differences in their concept images. What is needed, however, is more insight into how students' prior knowledge and experiences influence how they interpret their experiences in a calculus class.

\section{Discussion}

Mandisa, Themba, Ayanda and Nompilo are historically disadvantaged students while Matthew is a historically advantaged student. Megan and Deanne are the two historically advantaged educators. From their results, we notice that Mandisa, Themba, Ayanda and Nompilo have concept images that are mainly in the ratio layer with not more than two representations. Themba's concept image is mainly pseudo-structural throughout the three interviews, while Ayanda, Mandisa and Nompilo's concept images become more profound at the ratio layer by the third interview. Matthew has a very strong concept image which is in the ratio and limit layers and - in the third interview - with all representations present. He is able to describe the derivative as a process as well as an object. Megan and Deanne have concept images with three or more representations in each layer but Megan's limit layer is quite weak.

The question arising from these observations is "How can the historically disadvantaged students improve their concept images?” It is problematic that the course does not seem to manage to level out the differences more. On a positive note, some learning appears to have taken place for all students in the course, but the development of the historically advantaged student's concept image is so marked in comparison to the development of the historically disadvantaged students' concept images that it does raise some doubts about the extent to which the course is successful in assisting these students in making sense of the material and relating it to their previous experiences.

The analysis of Themba and Nompilo's results show that their concept images do not differ significantly from Ayanda and Mandisa's concept images, but their examination results show that they scored passing marks while Ayanda and Mandisa's examination results show that they were failing. This raises questions about the extent to which the examination written by these students captured conceptual aspects of calculus or mostly instrumental competency - or if the problem is in the interviewing or what can be captured by the theoretical framework. Future work will engage this, by interrogating the interplay between students, lecturer and materials.

\section{Notes}

${ }^{1}$ An 'Ex-Model C' school is a school that before 1994 catered for White students, and thus was more advantaged in terms of both financial and human resources. These schools are often still better off than many of their counterparts in the townships, with their better building and equipment and more financially affluent parent body which can then contribute financially to the running of the school. Thus, these schools are often more capable of attracting the best qualified teachers. Many parents from historically disadvantaged background choose to send their children to Ex-Model C schools in the hope that the advantage will benefit them. Thus, the learner body has become racially diversified, while in many cases the educator body remains dominantly White.

\section{References}

Amit, M., \& Vinner, S. (1990). Some misconceptions in calculus - anecdotes or the tip of an iceberg. In G. Booker, P. Cobb \& T.N. Mendicuti (Eds.), Proceedings of the Fourteenth International Conference for the Psychology of Mathematics Education Vol. 1 (pp. 3-10). Oaxtepec, Mexico.

Aspinwall, L., Shaw, K., \& Presmeg, N. C. (1997). Uncontrollable mental imagery: Graphical connections between a function and its derivative. Educational Studies in Mathematics, 33, 301-317. 
Bezuidenhout, J. G. H. (1998). Universiteitstudente se begryping van basiese begrippe in elementêre differensiaal-en integraalrekening. [University Students Understanding of Fundamental Calculus Concepts]. Unpublished doctoral dissertation, University of Stellenbosch, South Africa.

Bezuidenhout, J. (2001). Limits and continuity: some conceptions of first-year students. International Journal of Mathematical Education in Science and Technology, 32(4), 487-500.

Bowie, L. (1998). A Learning Theory Approach to Students' Misconception in Calculus. Unpublished masters thesis, University of Cape Town, South Africa.

Goldin, G., \& Shteingold, N. (2001). Systems of representations and the development of mathematical concepts. In A. Cuoco \& F. Curcio (Eds.), The roles of representation in school mathematics: National Council of Teachers of Mathematics 2001 Yearbook (pp. 1-19). Reston, VA: National Council of Teachers of Mathematics.

Gravemeijer, K. P., Lehrer, R., van Oers, H. J., \& Verschaffel, L. (Eds.). (2003). Symbolizing, modeling and tool use in mathematics education. Dordrecht, the Netherlands: Kluwer.

Guba, E. G., \& Lincoln, Y. S. (1989). Fourth generation evaluation. Newbury Park, CA: Sage.

Lithner, J. (2003). Students' mathematical reasoning in university textbook exercises. Educational Studies in Mathematics, 52, 29-55.

Orton, A. (1983). Students' understanding of differentiation. Educational Studies in Mathematics, 14(3), 235-250.

Parker, D. (2004). Mathematics and mathematics teaching in South Africa: Challenges for the university and the provincial Department of Education. In R. Belfour, T. Buthelezi \& C. Mitchell (Eds.), Teacher development at the centre of change (pp. 119-136). Durban: SEMI.

Selden, A., Selden, J., Hauk, S., \& Mason, A. (1999). Do calculus students eventually learn to solve non-routine problems? Cookeville, TN: Tennessee Technological University.
Sfard, A. (1991). On the dual nature of mathematical conceptions: Reflections on processes and objects as different sies of the same coin. Educational Studies in Mathematics, 22, 1-36.

Tall, D. (1993). Students' difficulties in calculus. In Proceedings of Working Group 3, 7th International Conference on Mathematical Education (pp. 13-28). Québec, Canada.

Tall, D., \& Vinner, S. (1981). Concept image and concept definition in mathematics with particular reference to limits and continuity. Educational Studies in Mathematics, 12, 151-169.

Thompson, P. W. (1994). Images of rate and operational understanding of the fundamental theorem of calculus. Educational Studies in Mathematics, 26, 229-274.

Ubuz, B. (2001). First year engineering students' learning of point of tangency, numerical calculation of gradients, and the approximate value of a function at a point through computers. Journal of Computers in Mathematics an Science Teaching, 20, 113-137.

Vinner, S., \& Dreyfus, T. (1989). Images and definitions for the concept of function. Journal for Research in Mathematics Education, 4, 356-366.

White, P., \& Mitchelmore, M. (1996). Conceptual knowledge in introductory calculus. Journal for Research in Mathematics Education, 27(1), 79-95.

Zandieh, M. J. (1997). The role of a formal definition in nine students' concept image of derivative. In S. Berenson, K. Dawkins, M. Blanton, W. Coulombe, J. Klob, K. Norwood \& L. Stiff (Eds.), Proceedings of the 20th Annual Meeting of the North American Chapter of the International Group for the Psychology of Mathematics Education (pp. 136-141). Columbus, OH: ERIC Clearinghouse for Science, Mathematics and Environmental Education.

Zandieh, M. J. (2000). A theoretical framework for analyzing student understanding of the concept of derivative. CBMS Issues in Mathematics Education, 8, 103-127. 